\title{
A Breakdown of Obligate Mutualism on a Small Island: An Interspecific Hybridization between Closely Related Fig Species (Ficus pumila and Ficus thunbergii) in Western Japan
}

\author{
Lum Tsai', Hiroshi Hayakawa², Tatsuya Fukuda ${ }^{3}$, Jun Yokoyama4* \\ ${ }^{1}$ Graduate Schools of Science and Engineering, Yamagata University, Yamagata, Japan \\ ${ }^{2}$ National Institute for Agro-Environmental Sciences, Tsukuba, Ibaraki, Japan \\ ${ }^{3}$ Faculty of Agriculture, Kochi University, Nankoku, Kochi, Japan \\ ${ }^{4}$ Faculty of Science, Yamagata University, Yamagata, Japan

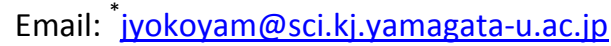

Received 19 December 2014; accepted 2 January 2015; published 15 January 2015

Copyright (C) 2015 by authors and Scientific Research Publishing Inc.

This work is licensed under the Creative Commons Attribution International License (CC BY). http://creativecommons.org/licenses/by/4.0/

\section{(c) (i) Open Access}

\section{Abstract}

Ficus (Moraceae) is a well-known group with specific pollination mutualisms, and hybridization is considered to be rare. Here, we report the presence of interspecific hybrids between Ficus pumila L. and F. thunbergii Maxim. on Okinoshima, a small island offshore of Shikoku, western Japan. AFLP (amplified fragment length polymorphism of genomic DNA) data suggested that more than one-fourth of individuals of morphological $F$. pumila were assigned as intermediate genotypes, suggesting hybrids. The hybridization between the two species was introgressive and unidirectional from $F$. thunbergii to $F$. pumila. The findings of this study, combined with other previous reports, suggest that the breakdown of mutualistic systems can occur in isolated populations such as those on islands.

\section{Keywords}

AFLP, Island, Hybridization, Ficus pumila, Ficus thunbergii, Western Japan

\footnotetext{
${ }^{*}$ Corresponding author.
}

How to cite this paper: Tsai, L., Hayakawa, H., Fukuda, T. and Yokoyama, J. (2015) A Breakdown of Obligate Mutualism on a Small Island: An Interspecific Hybridization between Closely Related Fig Species (Ficus pumila and Ficus thunbergii) in Western Japan. American Journal of Plant Sciences, 6, 126-131. http://dx.doi.org/10.4236/ajps.2015.61014 


\section{Introduction}

Ficus L. (Moraceae) comprises approximately 750 - 800 species mainly occurring in tropical regions throughout the world [1] [2]. The diversity center of the genus is Asia, and more than 450 species are distributed there [1]. Although the conspicuous diversity of this species is a significant point, Asia is also an important region for the evolution of the genus because it houses both of two major sexual expression modes in figs, monoecious and dioecious, with high species diversity in the latter. Most of the approximately 350 species of dioecious figs are distributed in Asia and show extreme variations in life-form, including trees, stranglers, shrubs, and climbing or trailing lianas [1]. These life-form variations are not observed in monoecious figs or figs in other regions. Thus, Asian figs have undergone many novel evolutionary events and are considered an important plant group for studying the evolution of life-form diversity.

Ficus is also well known as a genus with a specific plant-insect relationship. All fig species have their own specific pollinators originally derived from seed parasites (fig wasps, Agaonidae, Chalcidoidea, Hymenoptera). The interaction is a special case of obligate pollination mutualism and has long attracted the interest of many researchers [3]-[12]. This specific mode of pollination demonstrates another consequence of the evolution of figs. Although many plant groups experience frequent hybridization events during their evolution [13] [14], Ficus is usually considered an exception because of its specific pollination mode [2]. However, recent estimations from genetic data on six sympatric dioecious fig species in New Guinea suggested that $12 \%$ of fig populations included hybrids [15]. Conversely, the genetic identities of sympatric fig species were strictly maintained though fig-wasp species were shared among them [16]. Thus, additional examinations of other fig populations are necessary to confirm whether hybridization plays an important role in the evolution of fig species.

During our studies on population genetic structures and genetic differentiation in Japanese fig species, we identified new instances of hybridization between the closely related fig species Ficus pumila L. and Ficus thunbergii Maxim. on a small island off the shore of Shikoku, western Japan (Figure 1). Ficus pumila is widely distributed in Japan, Taiwan, China, and northern Indochina [17], whereas F. thunbergii is almost endemic to Japan (the Japanese archipelago and Cheju Island, Korea). These two species are closely related [17]. This occurrence, along with other cases reported previously, suggests that isolated places such as islands enhance the breakdown of specific relationships and hybridizations in closely related fig species.

\section{Materials and Methods}

Okinoshima is located off the shore of Kochi Prefecture, Shikoku, western Japan (Figure 2). We collected samples of $F$. pumila and F. thunbergii for analysis in 2010. Each sample was collected at least $50 \mathrm{~m}$ from neighboring samples to avoid resampling the same genets. Because not all individuals had syconia at the sampling time, we checked the morphological characteristics of leaves for exact identification of the two species when we collected samples: i.e., almost glabrous on the abaxial side and a lateral nerve angle of less than $40^{\circ}$ for $F$. pumila, and pubescens on the abaxial side and a lateral nerve angle of more than $50^{\circ}$ for $F$. thunbergii [17]. In total, 42 individuals of $F$. pumila and 2 individuals of $F$. thunbergii were collected. Voucher specimens were deposited at
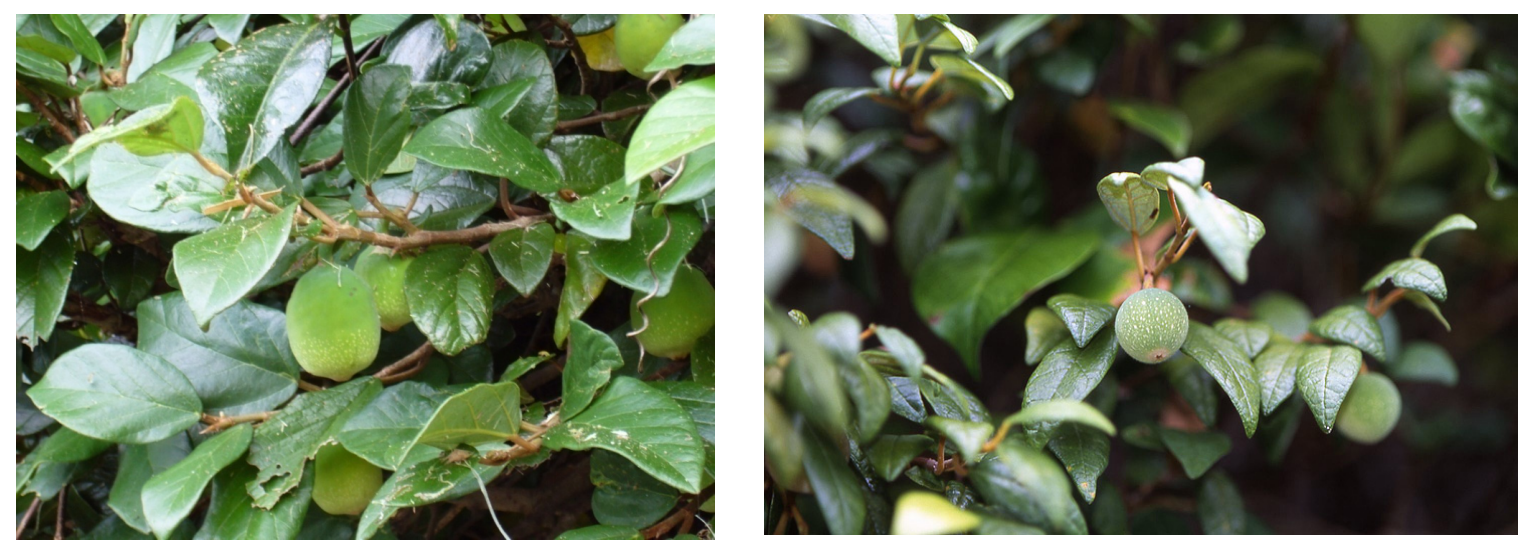

Figure 1. Appearances of two fig species used in this study. Left: Ficus pumila, right: F. thunbergii. Both photos were taken at Okinoshima, Kochi, western Japan. 


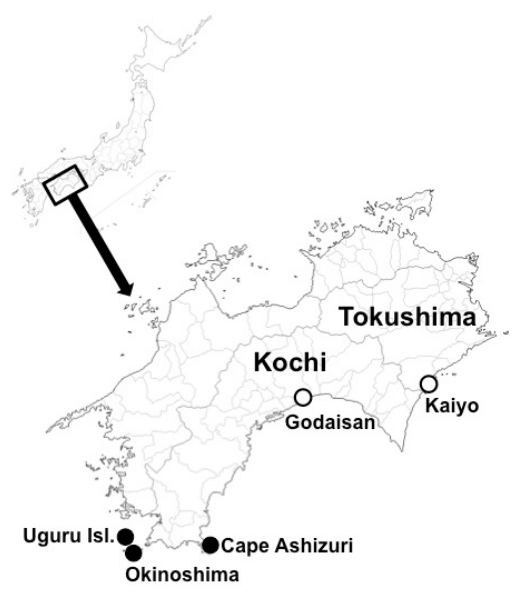

Figure 2. Sampling localities in this study. Solid circles indicate the sampling sites of $F$. pumila and open circles indicate those of $F$. thunbergii. Both species were collected from Okinoshima but main samples are F. pumila (42 of 44 samples).

the University Museum, Yamagata University. For comparisons, samples of $F$. pumila were collected from Uguru Island (17 individuals), a similar offshore island without F. thunbergii, as well as Cape Ashizuri (23 individuals) (Figure 2). We also collected $F$. thunbergii samples from Mt. Godaisan, Kochi City, Kochi Prefecture (14 individuals), and Kaiyo, a town in Tokushima Prefecture (14 individuals) (Figure 2).

The youngest leaf on the branch tip of each individual of F. pumila and $F$. thunbergii was collected and placed in a plastic bag with silica gel for storage until use. DNA extractions were performed using the DNeasy Plant Mini Kit (Qiagen, Hilden, Germany) following the manufacturer's instructions. Extracted DNA was frozen at $-20^{\circ} \mathrm{C}$ until use.

AFLP (amplified fragment length polymorphism) analyses [18] were performed using the Ligation and Preselective Amplification Module and selective primers (Applied Biosystems, Foster City, CA) following the manufacturer's protocol. Three primer pairs, EcoRI-ACA/MseI-CAA, EcoRI-ACC/MseI-CAA, and EcoRI-AAG/ MseI-CAA, were used for selective amplifications. The final amplification products were electrophoresed with the GeneScan ${ }^{\mathrm{TM}} 500$ Rox $^{\mathrm{TM}}$ dye Size Standard (Applied Biosystems) using an ABI PRISM ${ }^{\circledR} 310$ Genetic Analyzer (Applied Biosystems). We evaluated the peak pattern of the AFLP band using the analysis software GeneMapper (Applied Biosystems) in the range of 50 - $350 \mathrm{bp}$. Based on the AFLP data, an assignment test using Bayesian clustering was conducted using Structure 2.3.3 [19] [20]. An analysis was then performed with 25,000 iterations following 25,000 replications of burn-in period.

\section{Results and Discussion}

In total, 482 polymorphic bands (by three primer pairs) were detected from the five populations of $F$. pumila and F. thunbergii. Among these, 260 bands were observed from two populations of $F$. pumila (Uguru Island and Cape Ashizuri), and 274 bands were recorded from two populations of $F$. thunbergii (Godaisan and Kaiyo). In the analysis for $\mathrm{K}=2$ (assuming two genetic clusters representing species, $\mathrm{Ln}=-22262.1$; Figure 3), all individuals from Uguru Island and Cape Ashizuri were assigned as F. pumila (0.928 - 0.998), whereas all individuals from Mt. Godaisan and Kaiyo were assigned as F. thunbergii (0.968 - 0.998). Among the individuals from Okinoshima, two individuals of morphologically $F$. thunbergii were inferred as the same species, although the values were relatively low $(0.900,0.929)$. However, 11 of 42 individuals $(28.6 \%)$ of morphologically $F$. pumila individuals were assigned as intermediates between the two species (assigned to the F. pumila cluster: 0.167 0.661). This result indicated that interspecific hybridization had taken place between $F$. pumila and $F$. thunbergii; that hybrid individuals of the later generations existed, suggesting less or no hybrid sterility between the two species; and that unidirectional introgression from F. thunbergii to F. pumila had occurred on the island. This is the first report of the hybridization of Ficus in Japan as well as for Section Rhizocladus, one of the most speciesrich groups in warm-temperate and subtropical Asia. 


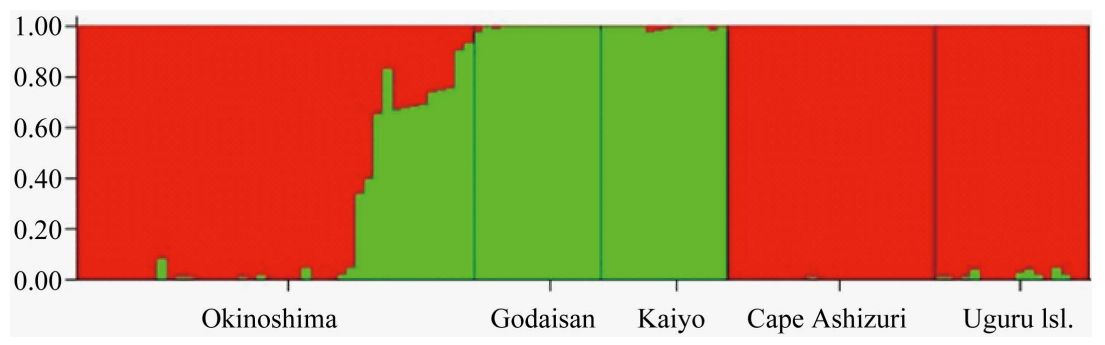

Figure 3. A result of assignment test for the AFLP data of $F$. pumila and $F$. thunbergii $(\mathrm{K}=2)$. A genetic cluster of $F$. pumila is indicated as red and that of $F$. thunbergii is as green. Sampling locations are indicated below of the bar plot. Two individuals at the rightmost of the Okinoshima window are F. thunbergii and others are F. pumila.

One of the reasons for unidirectional introgression may be the body size of fig wasps. The two fig species examined largely differ in the sizes of their syconia: i.e., the syconia of $F$. pumila are larger ( 3 - $4 \mathrm{~cm}$ in diameter) than those of $F$. thunbergii $(2 \mathrm{~cm})$. The size of syconia is also related to the size of flowers, and flower size is related to fig-wasp body size. Indeed, wasps from $F$. pumila were morphologically quite similar but slightly larger than those from F. thunbergii ([21]; J. Yokoyama, personal observations). Small wasps can enter the large syconia, but large wasps cannot enter the small syconia. This simple mechanism may control the direction of hybridization between these species.

The abundance of each species on the island may be another reason for unidirectional introgression. Among the difference of sampled individuals, the abundance of $F$. pumila was higher than that of $F$. thunbergii at Okinoshima. Under this situation, pollinating wasps of $F$. thunbergii likely encounter the absence of receptive syconia and may be forced to enter syconia of close relatives instead of the original fig partner. How often these mismatches occur should be confirmed in future field observations.

As indicated previously, interspecific hybridization of Ficus in nature is considered to be rare because of its specific pollination mechanisms [2]. Hybrid inviability may be another mechanism for preventing interspecific hybridizations [2]. However, recent studies indicate that natural hybridization should occur in closely related fig species. The first case confirmed using a molecular method was the hybridization between Ficus fistulosa Reinw. ex Blume and Ficus hispida L.f. in Indonesia [22], which also involved island populations. Jansen (1979) suggested that the breakdown of a specific mutualistic system, if it occurs, should be found in small populations such as those on islands [23]. To confirm this hypothesis, additional genetic analyses of figs with closely related sympatric species are needed.

Although the effects of hybridization on the evolution of Ficus are still unclear, note that a recent study suggested a hybrid origin of endemic fig species in the Ogasawara Islands, which are oceanic islands separated from the mainland by approximately $1000 \mathrm{~km}$ [24] (Note that this implication was based on the discordance of phylogenetic positions between figs and fig-wasps on the Ogasawara Islands, and not on the genomic admixture of figs). This case implies that hybridizations of Ficus, as in other plant groups, may have contributed to speciation. Therefore, the examination of other populations of endemic fig species in isolated areas such as oceanic islands is necessary.

\section{Conclusion}

Due to the nature of specific pollination mutualism, natural hybridization in Ficus has been underestimated. However, recent studies have shown that considerable instances in interspecific hybridization may have occurred in the genus. We have presented a new instance of such a hybridization from a small island in western Japan. These occurrences are most likely to be found in restricted areas such as islands where two or more closely related species are distributed. Although evolutionary roles remain unclear, interspecific hybridization in Ficus may have contributed to the diversification of the genus, particularly when considering cases in other angiosperms.

\section{Acknowledgements}

We thank Y. Kumekawa, K. Matsuyama, Y. Muramatsu, M. Muroi, K. Ohga, Y. Tsuchiya, and N. Yokoyama 
for their help in the course of this study. This study was partly supported by a Grant-in-Aid for Scientific Research from the Ministry of Education, Culture, Sports, Science and Technology, JAPAN (KAKENHI: No. 23370039 for J.Y. and T.F.).

\section{References}

[1] Corner, E.J.H. (1965) Check-list of Ficus in Asia and Australasia with Keys to Identification. Garden's Bulletin Singapore, 21, 1-186.

[2] Berg, C.C. and Wiebes, J.T. (1992) African Fig Trees and Fig Wasps. Koninklijke Nederlandse Akademie van Wetenschappen Verhandelingen Afdeling Natuurkunde, Tweede Reeks, Deel 89, Amsterdam.

[3] Ramirez, B.W. (1974) Coevolution of Ficus and Agaonidae. Annals of the Missouri Botanical Garden, 61, 770-780. http://dx.doi.org/10.2307/2395028

[4] Wiebes, J.T. (1979) Co-Evolution of Figs and Their Insect Pollinators. Annual Review of Ecology and Systematics, 10, 1-12. http://dx.doi.org/10.1146/annurev.es.10.110179.000245

[5] Berg, C.C. (1990) Reproduction and Evolution in Ficus (Moraceae): Traits Connected with the Adequate Rearing of Pollinators. Memoirs of the New York Botanical Garden, 55, 169-185.

[6] Herre, E.A., Machado, C.A., Bermingham, E., Nason, J.D., Windsor, D.M., McCafferty, S.S., van Houten, W. and Bachmann, K. (1996) Molecular Phylogenies of Figs and Their Pollinator Wasps. Journal of Biogeography, 23, 521530. http://dx.doi.org/10.1111/j.1365-2699.1996.tb00014.x

[7] Anstett, M.C., Hossaert-McKey, M. and Kjellberg, F. (1997) Figs and Fig Pollinators: Evolutionary Conflicts in a Coevolved Mutualism. Trends in Ecology and Evolution, 12, 94-98. http://dx.doi.org/10.1016/S0169-5347(96)10064-1

[8] Machado, C.A., Emmanuelle, J., Kjellberg, F., Compton, S.G. and Herre, E.A. (2001) Phylogenetic Relationships, Historical Biogeography and Character Evolution of Fig-Pollinating Wasps. Proceedings of the Royal Society of London $B$, 268, 685-694.

[9] Weiblen, G.D. (2001) Phylogenetic Relationships of Fig Wasps Pollinating Functionally Dioecious Figs Based on Mitochondrial DNA Sequences and Morphology. Systematic Biology, 50, 243-267. http://dx.doi.org/10.1080/10635150151125897

[10] Weiblen, G.D. and Bush, G.L. (2002) Speciation in Fig Pollinators and Parasites. Molecular Ecology, 11, $1573-1578$. http://dx.doi.org/10.1046/j.1365-294X.2002.01529.x

[11] Cook, J.M. and Rasplus, J.Y. (2003) Mutualists with Attitude: Coevolving Fig Wasps and Figs. Trends in Ecology and Evolution, 18, 241-248. http://dx.doi.org/10.1016/S0169-5347(03)00062-4

[12] Yokoyama, J. (2003) Cospeciation of Figs and Fig-Wasps: A Case Study of Endemic Species Pairs in the Ogasawara Islands. Population Ecology, 45, 249-256. http://dx.doi.org/10.1007/s10144-003-0166-4

[13] Arnold, M.L. (1997) Natural Hybridization and Evolution. Oxford University Press, Oxford.

[14] Rieseberg, L.H. and Carney, S.E. (1998) Plant Hybridization (Tansley Review, 102). New Phytologist, 140, 599-624. http://dx.doi.org/10.1046/j.1469-8137.1998.00315.x

[15] Moe, A.M. and Weiblen, G.D. (2012) Pollinator-Mediated Reproductive Isolation among Dioecious Fig Species (Ficus, Moraceae). Evolution, 66, 3710-3721. http://dx.doi.org/10.1111/j.1558-5646.2012.01727.x

[16] Wei, Z.D., Kobmoo, N., Cruaud, A. and Kjellberg, F. (2014) Genetic Structure and Hybridization in the Species Group of Ficus auriculata: Can Closely Related Sympatric Ficus Species Retain Their Genetic Identity While Sharing Pollinators? Molecular Ecology, 23, 3538-3550. http://dx.doi.org/10.1111/mec.12825

[17] Yamazaki, T. (1983) Taxonomic Review of the Moraceae from Japan, Korea, Taiwan and Adjacent Areas (2). Journal of Phytogeography and Taxonomy, 31, 1-15.

[18] Vos, P., Hogers, R., Bleeker, M., Reijans, M., van de Lee, T., Hornes, M., Frijters, A., Pot, J., Peleman, J., Kuiper, M. and Zabeau, M. (1995) AFLP: A New Technique for DNA Fingerprinting. Nucleic Acids Research, 23, 4407-4414. http://dx.doi.org/10.1093/nar/23.21.4407

[19] Pritchard, J.K., Stephens, M. and Donnelly, P. (2000) Inference of Population Structure Using Multilocus Genotype Data. Genetics, 155, 945-959.

[20] Falush, D., Stephens, M. and Pritchard, J.K. (2007) Inference of Population Structure Using Multilocus Genotype Date: Dominant Markers and Null Alleles. Molecular Ecology Notes, 7, 574-578. http://dx.doi.org/10.1111/j.1471-8286.2007.01758.x

[21] Yokoyama, J. and Iwatsuki, K. (1998) A Faunal Survey of Fig-Wasps (Chalcidoidea: Hymenoptera) Distributed in Japan and Their Associations with Figs (Ficus: Moraceae). Entomological Science, 1, 37-46.

[22] Parrish, T.L., Koelewijn, H.P., van Dijk, P.J. and Kruijk, M. (2003) Genetic Evidence for Natural Hybridization be- 
tween Species of Dioesious Ficus on Island Populations. Biotropica, 35, 333-343. http://dx.doi.org/10.1111/j.1744-7429.2003.tb00587.x

[23] Janzen, D.H. (1979) How to Be a Fig. Annual Review of Ecology and Systematics, 10, 13-51. http://dx.doi.org/10.1146/annurev.es.10.110179.000305

[24] Kusumi, J., Azuma, H., Tzeng, H.Y., Chou, L.S., Peng, Y.Q., Nakamura, K. and Su, Z.H. (2012) Phylogenetic Analyses Suggest a Hybrid Origin of the Figs (Moraceae: Ficus) that Are Endemic to the Ogasawara (Bonin) Islands, Japan. Molecular Phylogenetics and Evolution, 63, 168-179. http://dx.doi.org/10.1016/j.ympev.2012.01.004 
Scientific Research Publishing (SCIRP) is one of the largest Open Access journal publishers. It is currently publishing more than 200 open access, online, peer-reviewed journals covering a wide range of academic disciplines. SCIRP serves the worldwide academic communities and contributes to the progress and application of science with its publication.

Other selected journals from SCIRP are listed as below. Submit your manuscript to us via either submit@scirp.org or Online Submission Portal.
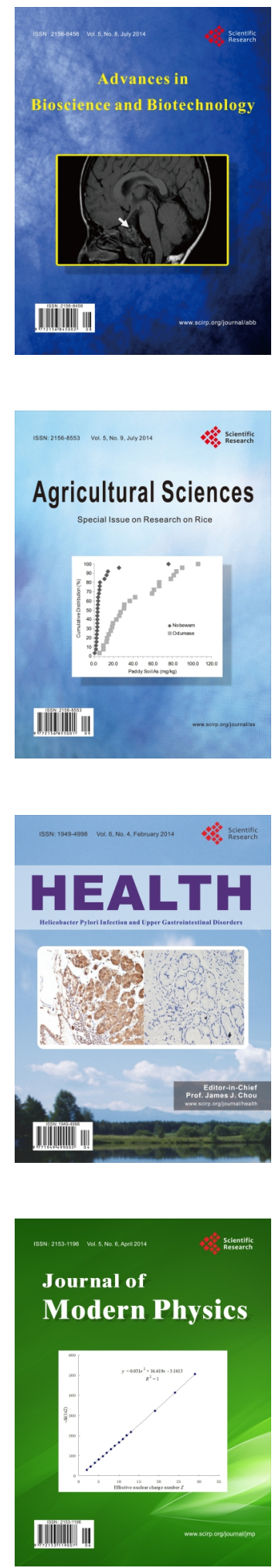
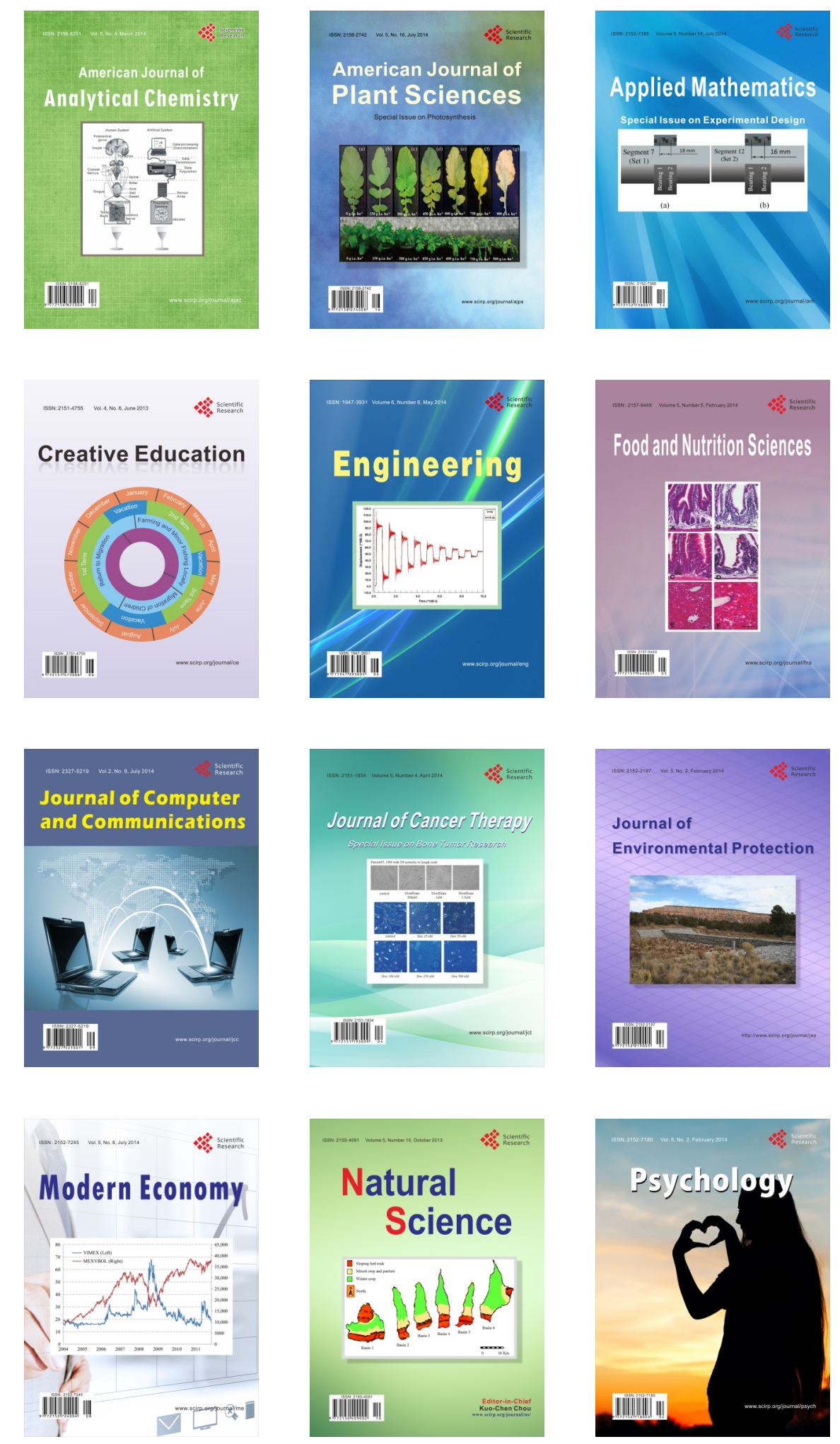